\title{
The perceived importance of prognostic aspects considered by physicians during work disability evaluation: a survey
}

\author{
Sylvia P. Snoeck-Krygsman 1,2,3* ${ }^{\mathbb{D}}$, Frederieke G. Schaafsma²,4, Birgit H. P. M. Donker-Cools 1,2,3,
} Carel T. J. Hulshof ${ }^{1,2}$, Lyanne P. Jansen ${ }^{1,2}$, René J. Kox ${ }^{3}$ and Jan L. Hoving ${ }^{1,2}$

\begin{abstract}
Background: Assessing prognosis is challenging for many physicians in various medical fields. Research shows that physicians who perform disability assessments consider six areas when evaluating a prognosis: disease, treatment, course of the disease, external information, patient-related and physician-related aspects. We administered a questionnaire to evaluate how physicians rate the importance of these six prognosis areas during work disability evaluation and to explore what kind of support they would like during prognosis assessment.
\end{abstract}

Methods: Seventy-six physicians scored the importance of 23 prognostic aspects distributed over six prognosis areas. Participants scored the importance of each aspect both "in general" and from the perspective of a case vignette of a worker with a severe degenerative disease. The questionnaire also covered needs and suggestions for support during the evaluation of prognoses.

Results: Medical areas that are related to the disease, or the treatment or course of the disease, appeared important (scores of 7.0-9.0), with less differing opinions among participants (IQR 1.0-3.0). Corresponding verbatim remarks supported the importance of disease and treatment as prognostic aspects. In comparison, patient- and physician-related aspects scored somewhat lower, with more variability (range 4.0-8.0, with IQR 2.0-5.0 for patient- and physicianrelated considerations). Participants indicated a need for a tool or online database that includes prognostic aspects and prognostic evidence.

Conclusions: Despite some variation in scores, the physicians rated all six prognosis areas as important for work disability evaluations. This study provides suggested aids to prognosis assessment, including an online support tool based on evidence-based medicine features.

Keywords: Prognosis (MeSH), Work (MeSH), Disability evaluation (MeSH), International classification of functioning, Disability and health (MeSH), Evidence-based medicine (MeSH)

*Correspondence: s.p.snoeck-krygsman@amsterdamumc.nl ${ }^{1}$ Department of Public and Occupational Health, Amsterdam Public Health Research Institute, Amsterdam UMC, Location Academic Medical Centre, Meibergdreef 15, 1105 AZ Amsterdam, The Netherlands Full list of author information is available at the end of the article

\section{Background}

Prognosis is the forecast of an outcome, and in a disability evaluation this outcome mainly concerns the functional abilities needed for work [1]. For example, will a 50 -year-old nurse with degenerative knee arthritis be able to climb stairs in the future? [2,3]. The evaluation of the prognosis is an important aspect of disability evaluations $[4,5]$ and has financial, personal, and legal consequences. 
Prognosis assessment is internationally considered to be one of four main tasks in disability evaluations [6], but physicians find the assessment of prognosis challenging $[7,8]$. Prognostic questions make up 39\% of physicians' information needs during disability evaluation [9].

A Dutch study identified 23 aspects for consideration in the prognosis evaluation during disability assessment [8]. These aspects fell into six areas: the specific disease or disorder, any treatment or potential treatment, the course of the disease, external information from other specialists or scientific evidence, patient-related aspects (e.g., coping), and physician-related considerations (e.g., role, empathy). However, it is not known how these aspects are valued and dealt with in practice. Although this qualitative study provided us with a range of aspects considered during prognosis assessment, it did not provide quantitative information on how important physicians rate these aspects or why some are considered more or less important. More insight into the importance of the aspects considered during prognosis assessment will also guide the development of a prognostic tool in the future.

Therefore, the purpose of this study was to evaluate how physicians rate the importance of six prognosis areas considered during work disability evaluation and to explore what kind of support they would like during prognosis assessment.

\section{Methods}

\section{Design}

In this study, we asked participants in a workshop to complete an anonymous paper questionnaire.

\section{Participants}

The study participants includes mainly social insurance physicians and occupational physicians, who assess a person's work capacity in the context of a disability benefit claim or with respect to reintegration, respectively. The participants attended an annual congress of the professional association for social insurance medicine in the Netherlands. The programme comprised several lectures and workshops, e.g. on prognosis assessment. This workshop involved a plenary presentation, followed by a case demonstration, discussions and the completion of an anonymous questionnaire. All procedures followed were in accordance with the ethical principles for medical research involving human subjects: before participants attended the workshop, they were informed about the study aim and procedure. Participation was voluntary; participants had the opportunity to discontinue at any time.

\section{The questionnaire}

Two authors (RK, JH) developed the questionnaire specifically for this study, it consisted of three parts. The first presented the 23 prognosis aspects found by Kox et al. [8]. The physicians were asked to rate the importance for the prognosis on a Likert scale ranging from 1 (not important at all) to 10 (of utmost importance), both for the presented case vignette (see Fig. 1) and "in general," that is, for any kind of patient. Each aspect was followed by an open question asking participants to motivate their answer, for example: "How important, in your opinion, is the severity of the disease for the prognosis? Please give a rating on a scale of 1 (not important at all) to 10 (of utmost importance) for this case vignette and in general." The second part consisted of five questions. Four were about encountered needs and solutions for the assessment of prognosis. The fifth asked whether the physician judged that the assessed limitations in functioning for the case vignette were permanent. The last part of the questionnaire consisted of questions concerning the respondent's characteristics, for example, age, sex, job area (e.g., social insurance medicine or occupational medicine), years of experience performing disability evaluations, and number of hours worked per week.

\section{Statistics and analyses}

The answers were stored and analyzed in IBM SPSS Statistics for Windows ${ }^{\circledR}$, version 25.0 (SPSS Inc., Chicago, IL, USA) using descriptive statistics. As most of the dependent variables from both the Likert scale questions and the demographic questions were not normally distributed, we calculated the median and interquartile range (IQR) to describe the distribution of the scores. The open answers were read and entered into SPSS by LJ; two researchers (SK and BD) double-checked these data. For the qualitative analyses, one researcher (SK) explored the answers and grouped them into themes; this process was then checked by three other researchers (JH, FS, BD, and LJ.)

\section{Results}

\section{Demographics}

Of the 78 physicians attending the workshop, 76 completed the questionnaire and handed it in after the workshop. The demographic questions in the last section of the questionnaire were completed by $53-55$ of all responders. Most of the participating physicians worked in social insurance medicine $(\mathrm{n}=35)$ or in occupational medicine $(n=15)$. Three participants worked in both these specialties and two worked in another medical specialty. A slight majority of the physicians were over 55 years old ( $n=31$, versus $n=23$ less than 55 years), 
This case vignette describes a person in the seventh decade of life with a degenerative neurological disorder, multiple system atrophy (MSA) parkinsonism, claiming a permanent disability pension. Snippets of research evidence related to MSA prognosis are provided to inform the rating of importance for the prognosis aspects.

\section{Characteristics of a worker claiming permanent disability pension}

- Patient: person about 65 years of age, fulltime employee on sick leave with fatigue, sleepiness, vertigo, amnesia, problems multitasking, slowness, rigidity, urge incontinence, sexual dysfunction, occasional trembling and trouble swallowing, mild anosmia.

- Diagnosis: multiple system atrophy parkinsonism (MSA-P) (based on profound autonomic dysfunction, symmetric parkinsonism, eye movement disorders, and early balance problems); MRI showed no specific MSA-P findings.

- Treatment: levodopa, since then less rigidity and no trembling. No side effects.

- Course: after several months with medication, still slowness, fatigue, mild cognitive impairment, normal muscle strength, still hypokinetic rigid syndrome, but now asymmetric, insecure gait.

- Opinion of treating physician (neurologist): progressive nature of the disease with gradually declining treatment options, participation in labor will be hard.

- Opinion of occupational physician: because of the functional impairments and prognosis, occupational rehabilitation is useless.

- Opinion of patient: permanently unable to work.

- Opinion of employer: was highly respected employee, however job functioning has now markedly declined, therefore employer thought it not possible to help employee by providing any occupational rehabilitation activities.

- Opinion of the physician performing the disability evaluation: patient will be able to perform physically light routine tasks, no multitasking or deadlines, recovery is not completely ruled out (MSA-P diagnosis not certain).

Evidence to inform the participants' prognostic judgment for this case vignette: three examples

- Dependent on localization, there are three subtypes. In subtype MSA-P, parkinsonism is a prominent symptom. 30-50\% of the patients have temporarily beneficial effects from levodopa (Factor SA, Doss Esper C. 1) Multiple system atrophy: Clinical features and diagnosis. 2) Multiple system atrophy: Prognosis and treatment. In Eichler AF (ed.), UpToDate. Waltham, Massachusetts: UpToDate, 2016. MSA (an atrophy of brain cells) is of unknown origin.

- $\quad$ This article states that the median time from onset of symptoms until combined motor and autonomic dysfunction is 2 years (range 1-10 years). The mean time interval until a walking aid, bedriddenness, and death is 3.5, 8, and 9 years, respectively. The combination of motor and autonomic dysfunction within 3 years after onset of symptoms is associated with a higher risk of a severe course and death. MSA-P has a more severe course than the cerebellar variant (MSA-C), but the survival time is similar. Older age is a risk factor for an earlier need of a wheelchair and for death. Changes on MRI (in pons and putamen) are more profound in advanced disease. (Watanabe H, Saito Y, Terao S, Ando T, Kachi T, Mukai E, Aiba I, Abe Y, Tamakoshi A, Doyu M, Hirayama M, Sobue G. (2002). Progression and prognosis in multiple system atrophy: an analysis of 230 Japanese patients. Brain, 125(5), 1070-1083.)

- $\quad$ This article describes some prognostic factors. Negative factors concerning survival are falling within 3 years after symptom onset (HR 2.3), bladder problems (HR 1.96), urine catheterization within 3 years after onset (HR 1,67), orthostatic intolerance after 1 year (HR 1,28), older age (HR 1,02), and autonomic dysfunction measured by the validated "autonomic severity score" (HR 1,07). (Coon EA, Sletten DM, Suarez MD, Mandrekar JN, Ahlskog, JE, Bower JH, Matsumoto JY, Silber MH, Benarroch EE, Fealey RD, Sandroni P, Low PA, Singer W. (2015). Clinical features and autonomic testing predict survival in multiple system atrophy. Brain, 138(12), 3623-3631.)

Fig. 1 Case vignette and examples of evidence provided to physicians 
most had been in the profession for over 15 years $(n=42$, versus $n=12$ less than 15 years), and most worked $32 \mathrm{~h}$ or more per week ( $n=40$, versus $n=13$ less than $32 h)$.

\section{Ratings of prognosis aspects relevant for the assessment of prognosis}

When the physicians were asked to rate the importance of the prognosis aspects "in general," their median scores varied between 6.0 and 8.0 (see Table 1). The median importance scores concerning the same prognosis aspects for the case vignette (person with MSA parkinsonism) were between 4.0 and 9.0. Interquartile ranges (IQRs) varied between 1.0 and 4.8 "in general" and between 1.0 and 5.0 for the case vignette.

For the prognosis aspects scored "in general," the first four prognostic areas (disease, treatment, course, and information) had median scores of 8.0, with IQRs of between 1.0 and 2.0. The remaining two areas-namely patient- and physician-related considerations-had more variable scores (i.e., medians ranged between 6.0 and 8.0), with IQRs of between 2.0 and 4.8.
In comparison, the case vignette had a somewhat higher importance score for severity of the disease (9.0), while prognosis aspects-such as disease-maintaining factors and vocational rehabilitation-had a somewhat lower score (7.0). From the interquartile ranges (IQRs), it can also be seen that physicians varied more in their assessment of, in particular, the patient- and physicianrelated considerations. Scores in the first four areas ranged between 7.0 and 9.0 with IQRs ranging from 1.0 to 3.0, whereas scores in the latter two varied between 4.0 and 7.0 with IQRs of between 3.0 and 5.0.

\section{Open questions on the motivation for the ratings}

Illustrative answers are shown in Table 2.

\section{Disease}

Some physicians stated that the nature and severity of the disease are a starting point for the assessment of the prognosis (e.g., \#42). Several physicians made it explicit that the degenerative, progressive nature of the disease is essential for the prognosis (e.g., \#32). It was also noted that in the case vignette, the progressive nature of the

Table 1 Importance scores of prognosis aspects $(n=76)$, "in general" and for the case vignette

\begin{tabular}{|c|c|c|c|c|c|}
\hline \multirow[t]{2}{*}{ Area } & \multirow[t]{2}{*}{$\begin{array}{l}\text { Prognosis aspects worth considering when evaluating } \\
\text { disability prognosis }\end{array}$} & \multicolumn{2}{|c|}{$\begin{array}{l}\text { Importance (1-10) } \\
\text { "In general" }\end{array}$} & \multicolumn{2}{|c|}{$\begin{array}{l}\text { Importance }(1-10) \\
\text { Case vignette }\end{array}$} \\
\hline & & Median & IQR & Median & IQR \\
\hline \multirow[t]{2}{*}{ 1. Disease } & Nature & 8.0 & 1.0 & 8.0 & 2.0 \\
\hline & Severity & 8.0 & 1.3 & 9.0 & 2.0 \\
\hline \multirow[t]{3}{*}{ 2. Treatment } & Type & 8.0 & 2.0 & 8.0 & 2.0 \\
\hline & Effect & 8.0 & 1.0 & 8.0 & 2.0 \\
\hline & Alternatives & 8.0 & 2.0 & 8.0 & 3.0 \\
\hline \multirow[t]{3}{*}{ 3. Course } & Course & 8.0 & 1.0 & 8.5 & 1.0 \\
\hline & Cause and disease maintaining factors & 8.0 & 1.5 & 7.0 & 3.0 \\
\hline & Aspects of revalidation and vocational rehabilitation & 8.0 & 1.5 & 7.0 & 3.0 \\
\hline \multirow[t]{2}{*}{ 4. Information and evidence } & Information from specialist/professional & 8.0 & 2.0 & 8.0 & 1.0 \\
\hline & Evidence from literature/guidelines/protocols & 8.0 & 1.3 & 8.0 & 2.0 \\
\hline \multirow[t]{7}{*}{ 5. Patient-related considerations } & Patients own vision concerning recovery & 8.0 & 4.0 & 6.0 & 5.0 \\
\hline & Work perspectives & 7.0 & 3.0 & 7.0 & 4.0 \\
\hline & Indirect advantage of being ill & 6.0 & 4.5 & 4.0 & 4.0 \\
\hline & Significance of work & 7.0 & 3.0 & 5.0 & 4.3 \\
\hline & Recovery behavior & 7.5 & 2.0 & 6.0 & 4.8 \\
\hline & Coping regarding disease or changed role & 8.0 & 2.0 & 6.0 & 4.0 \\
\hline & Psychosocial factors & 7.0 & 2.3 & 5.0 & 4.3 \\
\hline \multirow[t]{6}{*}{ 6. Physician-related considerations } & Perceived role & 7.0 & 3.0 & 5.0 & 4.0 \\
\hline & Empathy/compassion for the patient & 6.0 & 4.5 & 6.0 & 4.0 \\
\hline & Medical ethics & 6.5 & 4.0 & 7.0 & 4.8 \\
\hline & Influence of employer, colleagues, office culture & 6.0 & 4.8 & 5.0 & 4.8 \\
\hline & Patient observation and related physician impression & 7.0 & 2.0 & 7.0 & 3.0 \\
\hline & Anticipation of outcome & 6.0 & 3.0 & 6.0 & 4.5 \\
\hline
\end{tabular}

The number of answers varied per question, ranging from 64 to 76 ( $=84-100 \%$ of the participants) 
Table 2 Motivations accompanying the scores of importance (open questions) [Translated by the authors. Original source consisted of Dutch handwritten texts.]

\begin{tabular}{|c|c|c|}
\hline Area & \# & Quotes by participants \\
\hline \multirow[t]{3}{*}{ 1. Disease } & $\# 42$ & $\begin{array}{l}\text { For prognosis of future functioning, [the] disease (nature plus }{ }^{\text {a }} \text { severity) is [the] starting point for [the physician (]OP/ } \\
\mathrm{IP}^{\mathrm{b}}[\mathrm{D}] .[\ldots]\end{array}$ \\
\hline & \#32 & Main point being whether or not the disease is progressive \\
\hline & \#73 & $\begin{array}{l}\text { In the case vignette, it concerns a progressive disease; that certainly is determining for the prognosis. In general, } \\
\text { there are also situations in which the patient's coping is also an important factor, in addition to nature/severity of the } \\
\text { disease }\end{array}$ \\
\hline \multirow[t]{4}{*}{ 2. Treatment } & \#6 & $\begin{array}{l}\text { If there are several treatments available after the treatment that the client }{ }^{c} \text { is currently receiving, then [there] may be } \\
\text { a chance of improvement [of] work capacity }\end{array}$ \\
\hline & \#27 & $\begin{array}{l}\text { [Treatment] [e]ffect; can be [an] indication for influencing progression. [Judgment on treatment] [a]lternatives; } \\
\text { necessary for me for } N^{d} A^{d} \text {. No alternatives left equals }{ }^{e} \text { game over (end stage) }\end{array}$ \\
\hline & \#26 & In progressive diseases you are postponing [the] final state. In general: are there still valid treatment options? \\
\hline & \#52 & Treatment in this case vignette is aimed at treating symptoms. Not curative \\
\hline \multirow[t]{2}{*}{ 3. Course } & \#4 & Course, the past, tells something about the future \\
\hline & \#27 & Progressive disease, you want to know where [the patient] is on the downward line. The rest is not that important \\
\hline \multirow[t]{4}{*}{ 4. Information and evidence } & \#15 & $\mathrm{C}$ [Conclusion] of the treating neurologist (progressive complaints of illness) \\
\hline & \#23 & Evidence preponderates, [it] excludes bias in [the] treating physician \\
\hline & \#19 & Evidence [is] not necessary in most cases, because [they are] familiar, routine \\
\hline & \#36 & Especially with a substantial claim ([full disability pension/benefit,] IVA $\left.\backslash^{*} M E R G E F O R M A T d\right)$ info, evidence \\
\hline \multirow[t]{6}{*}{ 5. Patient-related considerations } & \#23 & $\begin{array}{l}\text { With a positive attitude [of the patient], the prognosis can turn out to be more favorable than the expectation [of the } \\
\text { prognosis for that disease mentioned] in the evidence }\end{array}$ \\
\hline & \#45 & $\begin{array}{l}\text { How the patient perceives }{ }^{f} \text { [his or her] complaints and }{ }^{g} \text { limitations plus } \backslash^{*} \text { MERGEFORMAT a advantages of being ill, } \\
\text { coping determines the prognosis for recovery }\end{array}$ \\
\hline & \#51 & $\begin{array}{l}\text { Given [the] age [of the] client } \backslash^{*} \text { MERGEFORMAT c, I would assign [a full disability pension/benefit,] IVA } \backslash^{*} M E R G E F O R- \\
\text { MATd }\end{array}$ \\
\hline & \#18 & Age. To evaluate doesn't equal " "to take into account."i Quality of life when client [is] continuing [to] work \\
\hline & \#26 & $\begin{array}{l}\text { In general, these are rather predictive aspects for success in vocational rehabilitation. Not often part of the considera- } \\
\text { tions [for] prognosis }\end{array}$ \\
\hline & \#46 & $\begin{array}{l}\text { [It] [i]s derived from literature that patient's opinion on duration of incapacity for work is an important prognostic } \\
\text { factor. On the other hand, the perception of the patient can be influenced by the messages physicians provide. So, I } \\
\text { see [the] perception of [the] patient as important and as influenceable }\end{array}$ \\
\hline \multirow[t]{9}{*}{ 6. Physician-related considerations } & \#72 & $\begin{array}{l}\text { Own impression plusa assessment is also very important on [sic] the individual client, in addition to the info practi- } \\
\text { tioner plusa available evidence }\end{array}$ \\
\hline & \#32 & I try to take these factors into account as little as possible \\
\hline & \#50 & $\begin{array}{l}\text { [There] is [a] good chance that [the physician,] OP/IPb[] takes "ethical" [sic] aspects into account; and certainly not if } \\
\text { there is a less serious/threatening condition }\end{array}$ \\
\hline & \#73 & $\begin{array}{l}\text { As [a physician performing disability evaluations,] IPj[]] you have to deal with a legal framework. The judgment must } \\
\text { be based on medical examination. The impression of the client can in my opinionk not always be leading. Especially } \\
\text { since there's a financial interest. [This] [a]lso applies to eg [sic] empathy/compassion for the client. [...] }\end{array}$ \\
\hline & \#45 & Physician bias plays a role too in assessing the prognosis \\
\hline & \#42 & $\begin{array}{l}\text { A client should receive the same outcome with every [individual physician,] OP/IPb. Role interpretations OP.IP [sic] } \\
\text { play no role then. I notice that I take patient's age into account. Say [the patient is] } 25 \text { years old... }\end{array}$ \\
\hline & \#24 & $\begin{array}{l}\text { Difficult to assign [a] gradation [to the] importance, because many factors are subconscious ["unconscious" in } \\
\text { original] }\end{array}$ \\
\hline & \#29 & Is influence [of] your personal blind spot too \\
\hline & \#27 & I base prognosis in $[\mathrm{sic}]$ a theoretical framework. I try to be as objective as possible, but aware of my own experiences \\
\hline
\end{tabular}

\footnotetext{
a Plus symbol in original

${ }^{b}$ Occupational physician and/or (social) insurance physician; both assess disabilities for work

'Patient in social security setting claiming disability benefits

${ }^{d}$ Permanent disability pension

e Equality symbol in original

${ }^{f}$ Brackets in original replaced by parentheses

${ }^{g}$ Ampersand in original

${ }^{\mathrm{h}}$ Inequality symbol in original
} 
Table 2 (continued)

'Quotation marks added for clarity

${ }^{j}$ Insurance physician. Evaluates functional abilities for work for claimants requesting disability benefits

${ }^{k}$ Abbreviated in original

disease was most important for prognosis, whereas in other cases other prognosis aspects might also be relevant (e.g., \#73).

\section{Treatment}

Considering treatment, many physicians evaluated the effect of the current one and looked for future options that could bring about a change (e.g., \#6, \#27). It was also pointed out that one should distinguish short-term treatment effects from long-term disease outcomes. In addition, physicians distinguished between relief of symptoms and curation (e.g., \#26, \#52).

\section{Course}

Regarding the course of the disease, physicians considered that the rate of progression of the disease and the results of treatment up to the moment of the disability evaluation forecast future developments (e.g., \#4). For the case vignette with a progressive medical disease, it was mentioned that the course of the illness (amount of deterioration over time) was of main importance (e.g., \#27).

\section{Information and evidence}

Information from the treating physician is considered important to get an insight into the patient's unique course and progressive symptoms (e.g., \#15). Some physicians stated that they preferred research evidence (e.g., \#23). Others pointed out that you may not need scientific literature in all cases (e.g., \#19), but you may need more evidence when a patient claims a large number of ongoing disabilities (e.g., \#36).

\section{Patient-related considerations}

Several patient-related factors, such as coping and the way patients perceive their illness, were considered important (e.g., \#23, \#45). Others spontaneously mentioned age as a patient-related ADP that either guides the decision (\#51) or does not (\#18). One physician (\#26) stated that patient-related factors can be important for vocational rehabilitation, but that they inform the physician conducting a disability evaluation to a lesser degree. Physicians also mentioned that it was important to assess whether patient-related prognosis aspects can be changed (e.g., \#46).

\section{Physician-related considerations}

Regarding the importance of physician-related factors, differing opinions were found, ranging from "very important" (e.g., \#72) to "as little as possible" (e.g., \#32), and some mentioned them to be case-dependent (e.g., \#50, \#73). Some physicians said that ethical aspects were considered (e.g., \#50) and that the physicians' own impressions were important (e.g., \#72), while others indicated that these should not be a part of the evaluation as they could unintentionally influence their judgment (e.g., \#73, \#32) or could bias the physician (e.g., \#45), and efforts should be made to ensure that a client receives similar outcomes from different assessors (e.g., \#42). However, it was also stated that these prognosis aspects are often hard to recognize, given their often subconscious nature (e.g., \#24). They are interrelated with a physician's "blind spot" (\#29), but it is important to be aware of those (e.g., \#27).

\section{Specific support that physicians suggest would aid them during the prognostic assessment}

Several answers illustrate additional needs, suggestions, and support for physicians during the assessment of prognosis (see Table 3). Principles of evidence-based medicine (EBM) were suggested as an integral part of the support (e.g., \#45, \#73), which could include evidencebased information on the nature (e.g., \#45) or course of a disease (e.g., \#73), treatment options, (e.g., \#45, \#73) and prognostic factors (e.g., \#8, \#16, \#32, \#77) that could be supported by figures, facts, and references (e.g., \#46). Some physicians mentioned that a potential tool should provide information about relevant prognosis aspects (e.g., \#58). The case vignette used might illustrate relevant prognostic information (e.g., \#41) as an example. A diagrammatic way of presenting information (such as checklists, programmed instructions, or flow charts) was also suggested (e.g., \#17).

\section{Type of aid}

As a preferred medium, digital aids were most frequently chosen (e.g., "website" $\mathrm{n}=38$, "app" $\mathrm{n}=17$ ). A desk pad format (a leaflet summarizing key remarks) was also considered useful $(\mathrm{n}=16)$.

\section{Discussion}

In this study we evaluated how physicians working in the field of disability evaluation rated the importance of six areas of prognosis, namely disease, treatment, course of the disease, external information, patient-related aspects, and physician-related aspects. Although all six areas were considered important, there was more consensus among 
Table 3 Potential elements of supportive aid for prognosis assessment (open and checkbox questions)

\begin{tabular}{|c|c|c|}
\hline \multirow{4}{*}{$\begin{array}{l}\text { Ingredients: } \\
\text { What should a prognosis assessment method provide you with? }\end{array}$} & \#46 & A simple instrument that can easily be used in practice \\
\hline & \#73 & $\begin{array}{l}\text { It must be evidence-based, identify treatment options for the disorder, course } \\
\text { of the disease }\end{array}$ \\
\hline & $\# 8$ & $\begin{array}{l}\text { I would prefer to have a document in which the pros and cons of the forecast } \\
\text { are weighed on the basis of current evidence }\end{array}$ \\
\hline & \#77 & Model to weigh factors \\
\hline \multirow{8}{*}{$\begin{array}{l}\text { Information in prognosis aid: } \\
\text { What information should this prognosis assessment aid contain? }\end{array}$} & $\# 41$ & All items mentioned in the case vignette \\
\hline & \#58 & Summary of relevant aspects \\
\hline & $\# 45$ & $\begin{array}{l}\text { Evidence-based information, info on the nature [of the] disease in time plus } \\
\text { therapeutic options }\end{array}$ \\
\hline & $\# 46$ & Figures, facts, and substantiation (references) \\
\hline & \#55 & $\begin{array}{l}\text { All necessary: (1) [is there complete work disability according to the labor } \\
\text { expert] }{ }^{\text {b }}(2) \text { search path (to be copied) in case of [a] possible [search in] Pub- } \\
\text { Med/Medline or other search (3) info [sic] about prognosis of the most com- } \\
\text { mon diseases (from relevant literature such as systematic reviews) }\end{array}$ \\
\hline & $\# 16$ & $\begin{array}{l}{[T \text { ] he most important factors you should take into account and what weight }} \\
\text { they carry for your judgment }\end{array}$ \\
\hline & \#32 & $\begin{array}{l}\text { Summary of known research about the disease. Prognostically favorable/unfa- } \\
\text { vorable factors }\end{array}$ \\
\hline & $\# 17$ & $\begin{array}{l}\text { [1]nstruction or checklist in a general sense. [W]ith psychological complaints } \\
\text { pay attention to a, b, c etc.[]] with neurologic [ones]: pay attention to a, b, c, etc. } \\
\text { So disease-related }\end{array}$ \\
\hline
\end{tabular}

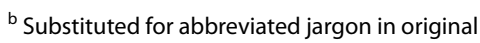

physicians concerning the three medical areas (disease, treatment, and course). The scores and verbatim remarks regarding the patient- and physician-related considerations (non-medical areas) reflected a more varied appreciation of importance among physicians.

Our use of a clear and severe medical case vignette may have influenced the physicians' more limited appreciation for non-medical prognosis aspects during the prognosis assessment. Verbatim remarks were made to the effect that medical considerations sufficed, and the importance of medical prognosis aspects appeared relatively high. In contrast, physicians' remarks regarding prognosis assessment of cases "in general," suggested that non-medical prognosis aspects could become more important in cases with a less clear medical background. Physician-related considerations appeared not to be given an explicit role in the assessment. Some physicians actually mentioned this and scores within this area appeared lower. However, it was also mentioned that they do play a relevant, though often implicit or subconscious, role.

As a form of support, physicians mentioned some kind of overview of prognosis aspects and relevant scientific evidence. A digital form of support was preferred.

\section{Comparison with the literature \\ The importance of the six areas of prognosis: diverging opinions on non-medical prognosis aspects}

In disability evaluations, the framework of the International Classification of Functioning, Disability and Health (ICF) [10] has been adopted by and used in several countries $[11,12]$. This classification system can also be used to describe work functioning, taking contextual and personal factors into account. However, there is some criticism that the ICF scheme is suggestive of the dominance of a medical perspective rather than a biopsychosocial one. Therefore, suggestions for a revision of the ICF have been made [13, 14]. For prognosis assessment in work disability evaluations, there is another problem with the ICF: The dynamic aspect of functioning and health over time is not addressed, nor are any consequent changes in activities or participation over time. As such, the use of the ICF during social-medical history taking and prognosis assessment is limited [11]. These two issues with the ICF (i.e., suggestive dominance of the medical perspective and absence of a time frame) leave room for diverging opinions $[15,16]$, especially regarding nonmedical aspects, which corresponds to our findings. 


\section{The importance of the six areas of prognosis: non-medical prognosis aspects}

Our study shows that the perceived relevance of patientrelated considerations varies in prognosis assessment. In the case of a clear medical condition, they might not all be necessary or might make a smaller contribution to the prognosis evaluation, whereas for medically unexplained physical symptoms (MUPS) or in vocational rehabilitation settings, physicians may attribute more value to them.

In a study on arguments used in disability prognosis [17], medical clarity contributed to the type and number of arguments used. In less clear medical cases, more arguments were used, including non-medical aspects such as coping or education. In addition, Ankersmit et al. [17] found that the expected outcome reception played a role: when disability claims were substantial or the chances of appeal were considered high, physicians preferred a more comprehensive evaluation of all potentially relevant aspects, including patient-related considerations (a preference that was also mentioned by physicians in our study). Another study [18], which concerned aspects for consideration in disability evaluation, suggested that the timespan covered in the evaluation (e.g., 5 days, 3 months, or 5 years) determined the value of the aspects used: For longer timespans, less relevance was attributed to patient-related factors. Some physicians in our study made explicit comments that in vocational rehabilitation settings, they would attribute more value to those patient-related prognosis aspects and that these could be targeted by interventions. Prognostic systematic reviews have shown that, regardless of context, patient-related factors, such as coping and self-efficacy, have more prognostic value for participation in work than factors of a medical nature [19-22] and could inform prognosis assessment and re-evaluations over time.

\section{The importance of the six areas of prognosis: implicit role of physician-related considerations}

Physician-related considerations were regarded by the physicians in our study as often subconscious factors that influence the physician's judgment. The consequences of those influences for prognosis assessment are mentioned in various medical studies within several fields [8, 23-25]. For example, physicians tend to express the prognosis in a way that is too optimistic. This could originate from, for example, a tendency to provide hope or to stimulate healthy rehabilitation and recovery behavior [8] and "not to harm" by taking those away [8, 24]. For example, an earlier study found that physicians performing disability assessments did not want to permanently deny young adults any hope or chance of future work participation [15], given the positive aspects of work. To overcome some of those consequences, physicians in our study said that the important thing is to be aware of these influences.

\section{The way to support physicians: EBM as core ingredient, covering relevant prognosis aspects}

The physicians in this study wanted support, including evidence-based prognostic information, preferably pre-appraised. Evidence should ideally be tailor-made, as suggested by earlier studies $[7,8]$. Even if prognostic evidence is present, it requires skills to find, appraise, and apply it in a particular case and within the countryspecific legislative context [26-28]. However, studies have demonstrated that training in evidence-based medicine may improve the quality of disability evaluations, prognosis assessment, and job satisfaction [4, 29]. Some physicians in our study mentioned that useful prognostic search strings might be provided, thus meeting the demand for help in finding prognostic evidence. This demand was also reported in other studies [26,30], which led to research providing potential search strategies, filters, or strings regarding themes such as prognosis and work participation [30-32]. The desire for user-friendliness, simplicity, and help in overseeing the various prognostic aspects was also identified by Kox et al. [8] and Louwerse et al. [33], both of whom were exploring possible prognostic tools. In contrast, when presented with possible prognostic tools, physicians also stressed the importance of preserving their professional autonomy to make unique, tailored evaluations. [34, 35] Moreover, they needed to become acquainted with them and they wanted to estimate their validity. [35]

\section{Strengths and limitations}

A strength of our study is that it combined insights from the quantitative data with qualitative data from corresponding remarks from physicians. However, our questionnaire was not suited for an in-depth exploration of the reasons why the importance was scored higher or lower. Also, we cannot exclude a selection effect, as the physicians attending the workshop may be more interested in this topic, but it is not clear how or in which direction this could have influenced the results.

The fact that the case vignette concerned a clear, severe medical condition might explain why the physicians did not elaborate much on the functional abilities of the patient. Some commented that this patient had no abilities for work at all and referred to the medical condition. It would be useful to evaluate the importance of prognostic aspects in a similar study that includes a case vignette with a less severe, chronic health condition (e.g., rheumatoid arthritis) or a condition with less medical clarity (e.g., MUPS). However, we tried to partially counter this 
disadvantage by asking for opinions on the prognosis for "general" cases, although we acknowledge that what is "general" could mean different things for the participants in this study.

\section{Conclusions}

This study demonstrated that all six areas of prognosis are important and that their individual contribution during prognosis assessment may vary from case to case. There is a need for evidence-based prognostic decisionmaking as well as tools to assist physicians in searching for, appraising, and applying prognostic evidence to substantiate their prognosis assessments.

\section{Abbreviations}

ADP(s): Aspect(s) of disability prognosis; EBM: Evidence-based medicine; ICF: International Classification of Functioning, Disability and Health; IQR: Interquartile range; MSA(-P): Multiple system atrophy (parkinsonism); MUPS: Medically unexplained physical symptoms; WMA: World Medical Association.

\section{Acknowledgements}

Not applicable.

\section{Authors' contributions}

All authors (SK, FS, BD, CH, LJ, RK and JH) contributed to the study conception and design. Material preparation and data collection were performed by $\mathrm{JH}$ and RK. Data transcription was performed by $L J$ and checked by SK and BD. Data entry into SPSS was performed by LJ. Data analysis was performed by SK and checked by $L, B D, J H$ and FS. The first draft of the manuscript was written by SK. FS, JH, BD commented on previous versions of the manuscript. All authors (SK, FS, BD, CH, $\sqcup, \mathrm{RK}$ and $\mathrm{JH}$ ) read and approved the final manuscript. All authors (SK, FS, BD, CH, LJ, RK and JH) have agreed to be personally accountable for his or her own contributions and have ensured that questions related to the accuracy or integrity of any part of the work, even ones in which the author was not personally involved, are appropriately investigated resolved, and the resolution will be documented in the literature. All authors read and approved the final manuscript.

\section{Funding}

The project was financed by the Dutch Institute of Employee Benefit Schemes (UWV), Amsterdam, on behalf of the Research Center for Insurance Medicine (KCVG). However, no funding bodies had any role in the study design, data collection, and analysis, decision to publish, or preparation of the manuscript.

\section{Availability of data and materials}

The datasets generated during and/or analyzed during the current study are available from the corresponding author on reasonable request.

\section{Declarations}

\section{Ethics approval and consent to participate}

This study did not entail medical research, because the human subjects were not patients nor were they involved in clinical health care. Their data, namely their responses to a questionnaire on content and opinions, were retrieved anonymously and were never identifiable. Therefore, the research team concluded that the research was not subject to the WMA Declaration of Helsinki [36].

\section{Consent for publication}

Not applicable.

\section{Competing interests}

The authors declare no conflict of interest nor any competing interests.

\section{Author details}

${ }^{1}$ Department of Public and Occupational Health, Amsterdam Public Health Research Institute, Amsterdam UMC, Location Academic Medical Centre, Meibergdreef 15, 1105 AZ Amsterdam, The Netherlands. ${ }^{2}$ Research Center for Insurance Medicine (KCVG): collaboration between AMC-UMCG-UWVVUmc, Amsterdam, The Netherlands. ${ }^{3}$ Department of Social Medical Affairs (SMZ), The Dutch Social Security Institute: The Institute for Employee Benefits Schemes (UWV), La Guardiaweg 94-114, 1043 DL Amsterdam, The Netherlands. ${ }^{4}$ Department of Public and Occupational Health, Amsterdam Public Health Research Institute, Amsterdam UMC, Vrije Universiteit Amsterdam, Van der Boechorststraat 7, 1081 BT Amsterdam, The Netherlands.

Received: 30 October 2020 Accepted: 15 January 2022

Published online: 29 January 2022

\section{References}

1. LISV. Professionele herbeoordeling verzekeringsarts - Standaard. [Dutch National Institute for Social Security (LISV): professional re-evaluation by the insurance physician - Standard.] Amsterdam: Landelijk Instituut Sociale Verzekeringen; 2000. p. 1-11.

2. Emanuel EJ, Emanuel LL. The promise of a good death. Lancet. 1998;351:SII21-9.

3. Mathers CD, Loncar D. Projections of global mortality and burden of disease from 2002 to 2030. PLoS Med. 2006:3(11):e442.

4. Kok R, Hoving JL, Verbeek JH, Schaafsma FG, Smits PB, van Dijk FJ. Evaluation of a workshop on evidence-based medicine for social insurance physicians. Occup Med. 2008;58(2):83-7.

5. Anner J, Kunz R, Boer WD. Reporting about disability evaluation in European countries. Disabil Rehabil. 2014;36(10):848-54.

6. de Boer W. Quality of evaluation of work disability. Academisch proefschrift Universiteit van Amsterdam Hoofddorp 2010.

7. Hoving $\mathrm{J}$, van der Voort R, Kok R, Verbeek JH, Hulshof CT. Het belang van een onderbouwde prognose en de rol van evidence daarbij: een survey onder verzekeringsartsen [The importance of a substantiated prognosis and the role of prognostic evidence: a survey among insurance physicians]. TBV-Tijdschrift voor Bedrijfs-en Verzekeringsgeneeskunde. 2016;24(10):465-71.

8. Kox RJ, Hoving JL, Verbeek JH, Schouten MJ, Hulshof CT, Wind H, FringsDresen $\mathrm{MH}$. Assessment of prognosis by physicians involved in work disability evaluation: a qualitative study. PLoS ONE. 2019;14(2):e0212276.

9. Kok R, Hoving JL, Verbeek JH, van Dijk FJ. What knowledge questions do physicians have while performing disability evaluations and which sources do they use? Evid Based Disabil Eval. 2014;1:19.

10. World Health Organization. International classification of functioning, disability and health: ICF. Geneva: World Health Organization; 2001.

11. Anner J, Schwegler U, Kunz R, Trezzini B, de Boer W. Evaluation of work disability and the international classification of functioning, disability and health: what to expect and what not. BMC Public Health. 2012;12(1):470.

12. LISV: Medisch arbeidsongeschiktheidscriterium - Richtlijn. [Dutch National Institute for Social Security (LISV): Criterium medical disabilities for work - Guideline.] Amsterdam: Tijdelijk Instituut Coördinatie en Afstemming (TICA); 1996. p. 1-25.

13. Heerkens YF, de Weerd $M$, Huber $M$, de Brouwer $C P$, van der Veen $S$, Perenboom RJ, van Gool CH, ten Napel H, van Bon-Martens M, Stallinga HA. Reconsideration of the scheme of the international classification of functioning, disability and health: incentives from the Netherlands for a global debate. Disabil Rehabil. 2018;40(5):603-11.

14. Heerkens YF, de Weerd M, Huber M, de Brouwer CP, van der Veen S, Perenboom RJ, van Gool CH, Ten Napel H, van Bon-Martens M, Stallinga HA. Reconsideration ICF scheme. Disabil Rehabil. 2018:40(1):121-2.

15. Anner J, Brage S, Donceel P, Falez F, Freudenstein R, Oancea C, de Boer W. Validation of the EUMASS Core Set for medical evaluation of work disability. Disabil Rehabil. 2013;35(25):2147-56.

16. Brage $S$, Donceel P, Falez F. Development of ICF core set for disability evaluation in social security. Disabil Rehabil. 2008;30(18):1392-6.

17. Ankersmit JF, Chan WK, Kok R, Wind H, Hoving J. Onderbouwing van de duurzaamheid bij Wajong 2015 beoordelingen. [Substantiation of the permanence [of disabilities for work - 24 Ed.]] in assessments according to Wajong 2015 [Dutch law regarding benefits for handicapped 
youth - Ed.].] TBV-Tijdschrift voor Bedrijfs-en Verzekeringsgeneeskunde 2018; 26(10):518-525.

18. Slebus FG, Sluiter JK, Kuijer PPF, Willems JH, Frings-Dresen MH. Workability evaluation: a piece of cake or a hard nut to crack? Disabil Rehabil. 2007;29(16):1295-300

19. Vooijs M, Leensen MC, Hoving JL, Daams JG, Wind H, Frings-Dresen $\mathrm{MH}$. Disease-generic factors of work participation of workers with a chronic disease: a systematic review. Int Arch Occup Environ Health. 2015:88(8):1015-29.

20. Detaille SI, Heerkens YF, Engels JA, Van Der Gulden JW, Van Dijk FJ. Common prognostic factors of work disability among employees with a chronic somatic disease: a systematic review of cohort studies. Scand J Work Environ Health. 2009;35:261-81.

21. Cornelius L, van der Klink J, Groothoff J, Brouwer S. Prognostic factors of long term disability due to mental disorders: a systematic review. J Occup Rehabil. 2011;21(2):259-74.

22. Dekkers-Sánchez PM, Wind H, Sluiter JK, Frings-Dresen MH. What factors are most relevant to the assessment of work ability of employees on long-term sick leave? The physicians' perspective. Int Arch Occup Environ Health. 2013:86(5):509-18.

23. Pontin $\mathrm{D}$, Jordan N. Issues in prognostication for hospital specialist palliative care doctors and nurses: a qualitative inquiry. Palliat Med. 2013;27(2):165-71.

24. Muller E, Hoving J. Visie van verzekeringsartsen op de claimbeoordeling van mensen met een beperkte levensverwachting [Opinions of insurance physicians on the claim assessment for patients with poor life expectancy]. TBV-Tijdschrift voor Bedrijfs-en Verzekeringsgeneeskunde. 2018;26(10):533-7.

25. An HJ, Jeon HJ, Chun SH, Jung HA, Ahn HK, Lee KH. Kim M-h, Kim JH, Cheon J, Kim J: Feasibility study of physician orders for life-sustaining treatment for patients with terminal cancer. Cancer Res Treat Off J Korean Cancer Assoc. 2019;51(4):1632.

26. Kok R, Hoving JL, Verbeek J, Schaafsma FG, van Dijk FJ. Integrating evidence in disability evaluation by social insurance physicians. Scand J Work Environ Health. 2011;37:494-501.

27. Schaafsma F, Hoving J. Prognose en het gebruik van evidence bij werkhervatting [Prognosis and the use of evidence in [assisting with - Ed] return to work]. TBV-Tijdschrift voor Bedrijfs-en Verzekeringsgeneeskunde. 2016;24(10):487-90.

28. Van der Hoek W. Prognose van depressie in het kader van de claimbeoordeling voor de nieuwe WAO. [Prognosis of major depressive disorder in the context of the claim assessment for the new WAO [Dutch disability insurance law - Ed.].] TBV-Tijdschrift voor Bedrijfs-en Verzekeringsgeneeskunde 2006;14(4):192-197.

29. Hoving JL, Kok R, Ketelaar SM, Smits PB, van Dijk FJ, Verbeek JH. Improved quality and more attractive work by applying EBM in disability evaluations: a qualitative survey. BMC Med Educ. 2016;16(1):77.

30. Haafkens J, Moerman C, Schuring M, van Dijk F. Searching bibliographic databases for literature on chronic disease and work participation. Occup Med. 2005;56(1):39-45.

31. Geersing G-J, Bouwmeester W, Zuithoff P, Spijker R, Leeflang M, Moons K. Search filters for finding prognostic and diagnostic prediction studies in Medline to enhance systematic reviews. PLoS ONE. 2012;7(2):e32844.

32. Kok R, Verbeek JA, Faber B, van Dijk FJ, Hoving JL. A search strategy to identify studies on the prognosis of work disability: a diagnostic test framework. BMJ Open. 2015;5(5):e006315.

33. Louwerse I, Huysmans MA, van Rijssen JHJ, Overvliet J, van der Beek AJ, Anema JR. Preferences regarding the way of use and design of a work ability prognosis support tool: a focus group study among professionals. Disabil Rehabil. 2019;43:2031-7.

34. van Muijen P, Duijts SF. Kornet-van der Aa DA, van der Beek AJ, Anema $J R$ : Work disability assessment of cancer survivors: insurance physicians' perspectives. Occup Med (Lond). 2015;65(7):558-63.

35. Louwerse I, Huysmans M, van Rijssen H, Gielen C, van der Beek A, Anema J. Use of a decision support tool on prognosis of work ability in work disability assessments: an experimental study among insurance physicians. J Occup Rehabil. 2020;31:185-96.

36. World Medical Association. World Medical Association Declaration of Helsinki: ethical principles for medical research involving human subjects. JAMA. 2013;310(20):2191-4

\section{Publisher's Note}

Springer Nature remains neutral with regard to jurisdictional claims in published maps and institutional affiliations.
Ready to submit your research? Choose BMC and benefit from:

- fast, convenient online submission

- thorough peer review by experienced researchers in your field

- rapid publication on acceptance

- support for research data, including large and complex data types

- gold Open Access which fosters wider collaboration and increased citations

- maximum visibility for your research: over $100 \mathrm{M}$ website views per year

At BMC, research is always in progress.

Learn more biomedcentral.com/submissions 